\title{
Torque Measurement Methods for Very High Speed Synchronous Motors
}

Pierre-Daniel Pfister, Student Member IEEE and Yves Perriard, Senior Member IEEE

Laboratory of Integrated Actuator (LAI), Ecole Polytechnique Fédérale de Lausanne (EPFL), 1015 Lausanne, Switzerland e-mail: pierre-daniel.pfister@epfl.ch

\begin{abstract}
The article presents two different torque measurement methods for very high speed synchronous motors: one uses an eddy current brake, and the other is an inertial method. The article also presents a ball bearings friction torque measurement method designed for very high speeds.
\end{abstract}

Index Terms - Very high speed motor, Torque measurements, Inertia, Ball bearing, Eddy current brake.

\section{INTRODUCTION}

The increasing need for low weight, high efficiency and high power density motors or generators has led to an intense research and development in the field of very high speed (VHS) motor or generators [1], [2].

The measuring process is inherently linked with the target speed and power of the machine. Our goal is the measurement of a 200 '000 rpm, $2 \mathrm{~kW}$ synchronous machine [3]. Traditional measurement tools are not compatible with such high speeds. It is then necessary to develop new ones. In this article we present different aspects which need to be considered for torque measurement, and two measurement methods.

At a very high speed, it is highly recommended not to make a mechanical connection between the motor and the measuring device, as it would add normal modes. If a measuring device is mechanically connected and held through bearings, then the whole design would be hyperstatic. If the device is not held through bearings, then the shaft is longer and the normal modes are lower. Since at high speeds the normal modes are at the order of magnitude of the target speed, such lengthening can be fatal.

The goal was then to develop contactless torque measurement methods. Using some of the concepts developed in one of these methods, a second part of the article will present a method for ball bearings friction torque measurements.

\section{Proctection}

The first question to consider in design of high speed measurement tools is the safety. In our prototype, the rotor at $200 \mathrm{krpm}$ has $350 \mathrm{~J}$ of kinetic energy. It is then necessary to build a housing which can stand defects. In our case, the protection is made of two polycarbonate shells of $6 \mathrm{~mm}$ each, one inside the other. A moving protective cover made of 5 $\mathrm{mm}$ thick steel is added to the protection. The advantage of this design is to have transparency and security.

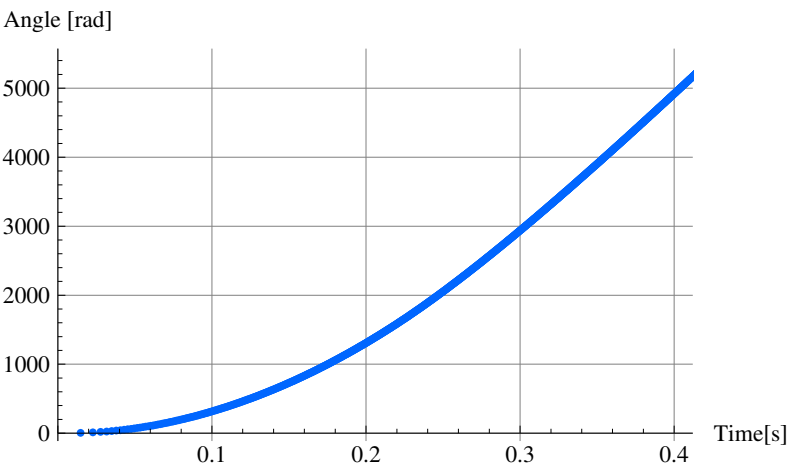

Fig. 1. Position of the rotor.

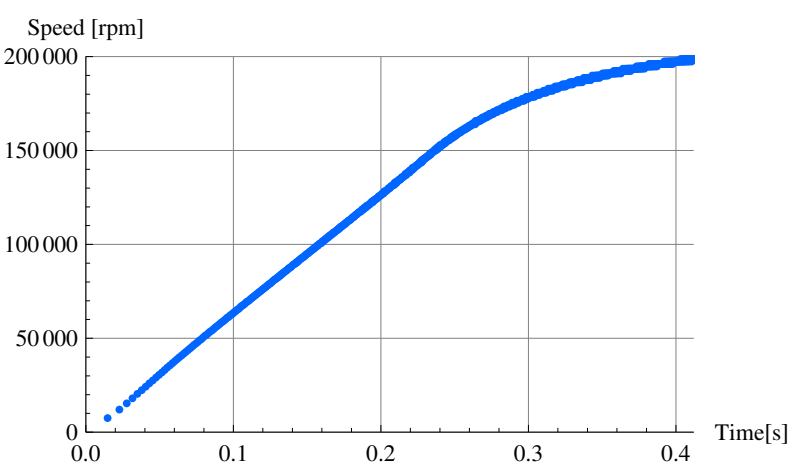

Fig. 2. Rotor speed obtained by numerical differentiation.

\section{MOTOR TORQUE MEASUREMENT: INERTIAL METHOD}

\section{A. Method}

This basic method is based only on the inertia of the motor rotor. A coder measures the position $\alpha$ of the rotor. The acceleration $\ddot{\alpha}$ of the rotor is related to the frequency $f_{c}$ of the coder with resolution $n$ as:

$$
\ddot{\alpha}=\frac{2 \pi}{n} \dot{f}_{c}
$$

Knowing the inertia $I$ we obtain the torque $T$ that needs to be applied to produce the acceleration $\ddot{\alpha}$ :

$$
T=I \ddot{\alpha}
$$

In our case the inertia of the rotor $I=1.5951 \times 10^{-6} \mathrm{~kg} \mathrm{~m}^{2}$. 


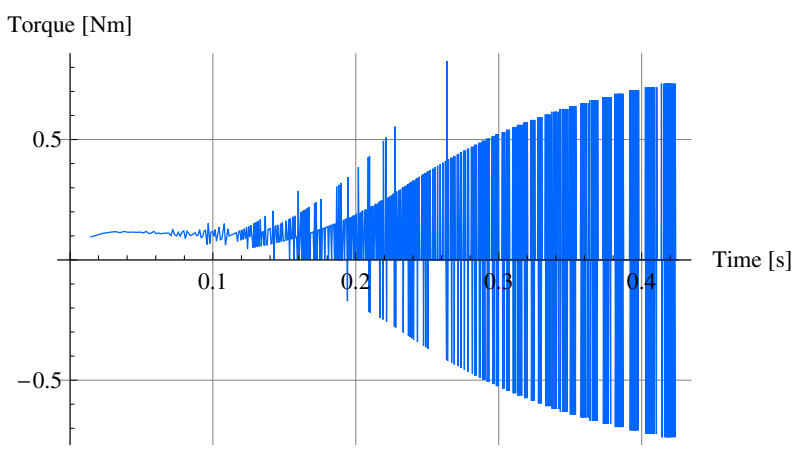

Fig. 3. Motor torque obtained by numerical differentiation. The useful information is hidden in the noise.

The value of $n$ needs to be compatible with low and high speeds. Fig. 1 shows the angle $\alpha$ measured by the coder with $n=1$. A numerical differentiation allows us to obtain the rotor speed (Fig. 2). Using a numerical differentiation once again, the torque is computed (Fig 3). The noise in the measurements makes a numerical differentiation useless. In Figs 1 to 6 , the applied voltage is $70 \mathrm{~V}$. The current is limited from 0 to $\sim 220$ ms.

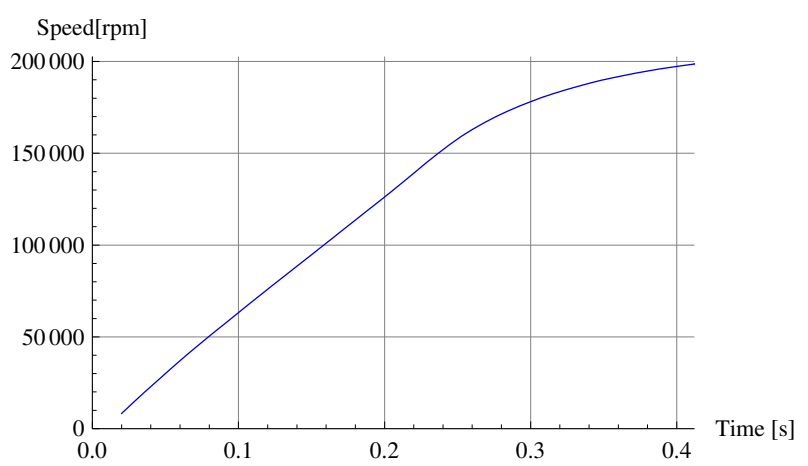

Fig. 4. Speed as the function of time obtained by analytical differentiation.

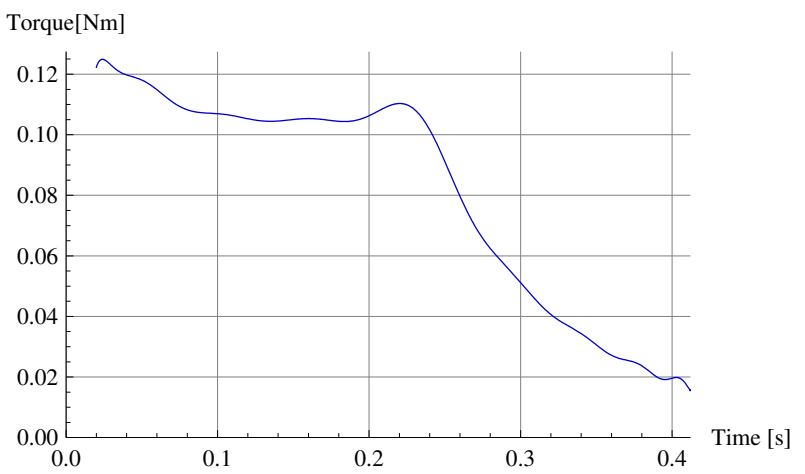

Fig. 5. Torque as a function of time obtained by analytical differentiation.

The solution for eliminating this noise is to do first a polynomial fitting (of order 40 for example) of the curve

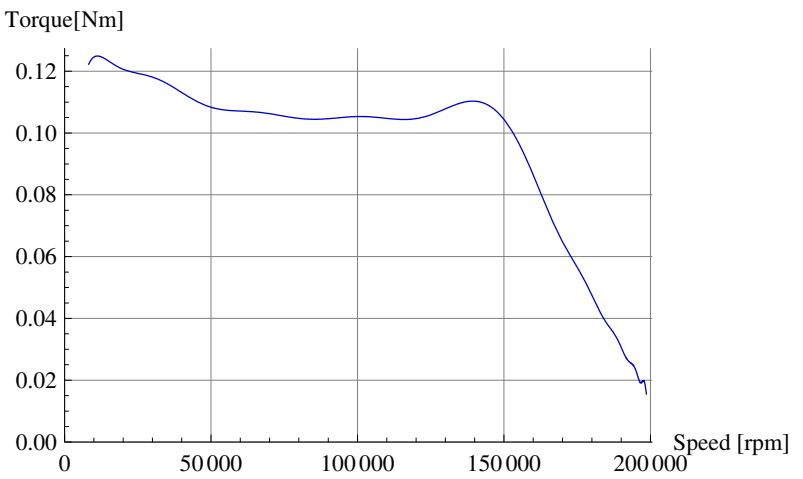

Fig. 6. The torque as a function of speed.

representing the rotor position as a function of the time and then differentiate analytically. Fig. 4 represents the speed as a function of time. A second analytical derivative is calculated to obtain the torque (Fig. 5). This method is powerful to cancel the noise.

Before the fitting, a resampling can be done, because there are more points per unit of time at high speed than at low speed.

\section{B. Results}

The combination of the speed and the torque functions (Figs 4 and 5) gives us the torque vs. speed curve. The result obtained with our motor prototype driven at $70 \mathrm{~V}$ is shown in Fig. 6. We see the current limitation from $0 \mathrm{krpm}$ to $\sim 140$ krpm.

\section{MOTOR TORQUE MEASUREMENT: EDDY CURRENTS BRAKE METHOD}

\section{A. Brake design}

In this method, a braking torque is created and measured. Because of the high power density, temperatures in the motor are critical. The braking torque dissipates losses. It is important that the heat is created in a piece which is not in contact with the motor. This is why a the following eddy current brake is made.

A multipolar axially magnetized permanent magnet is mounted at the end of the motor shaft (Fig. 7). A copper plate is placed in front of the magnet. As the plate is placed in a varying field, eddy currents appear in it and a braking torque appears. A torquemeter measures the torque applied on the plate.

\section{B. The finite element model}

A finite element model (FEM) of the eddy current brake (Fig. 8) was based on the following simplifying assumptions, shown in Fig. 7:

1) The multipolar moving magnet is replaced by static multiphase windings with a phase shift between the 


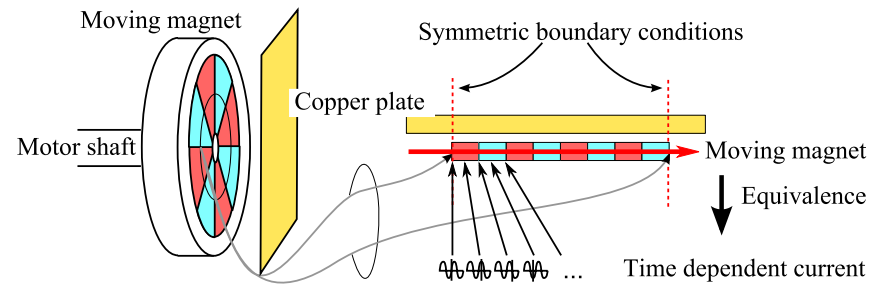

Fig. 7. Eddy current brake design and assumptions for eddy current brake FEM model.

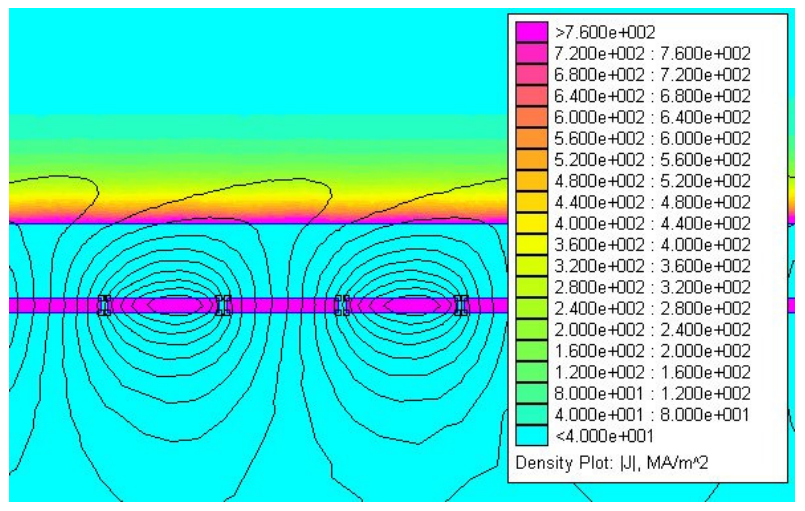

Fig. 8. Model of the magnetic field and the magnitude of the current density at 200 '000 rpm. We see the skin effect in the copper plate.

currents in the phases. The problem becomes a static time-harmonic problem.

2) We look at the field along the circumference which is midway in-between the inner and the outer radius. The circumference is "opened" and the rotating configuration is approximated by a linear one. This allows us to use FEMM which is a 2D FEM software.

3) The current value is chosen so that the first harmonic of the flux density due to the currents is equal to the first harmonic of the flux density due to the brake permanent magnet.

\section{Prototype}

Different brake prototypes were made. In this article the brake has 5 pole pairs. The amplitude of the magnetic flux density is measured using a hall probe at different distances from the magnet. The value of the amplitude of magnetic flux density at the surface of the magnet is estimated to be $0.512 \mathrm{~T}$ by extrapolation. The brake dimensions are presented in Tab. I.

TABLE I

BRAKE DIMENSIONS AND MATERIALS

$\begin{array}{ll}\text { Magnet inner radius } & 4 \mathrm{~mm} \\ \text { Magnet outer radius } & 6.225 \mathrm{~mm} \\ \text { Axial magnet thickness } & 2.3 \mathrm{~mm} \\ \text { Yoke material (behind the magnet) } & \text { Nickel-iron } \\ \text { Magnet material } & \text { NdFeB (Vacodym 677 HR) }\end{array}$

\section{Results}

Other articles give a better accuracy of results [4], but the merit of our model (the results are shown in Fig. 9) is to give a good insight into the problem, given the simplicity of the model which is static and 2D. The model and the prototypes allowed us to conclude the following about the design of the brake:

1) The number of pole pairs is an important factor at low speeds, but not at high speeds because of the skin effect.

2) Variations around the given value of the magnet thickness do not change the braking torque significantly.

3) The remanent field of the magnet is critical, it increases the torque in a non linear way.

4) The resistivity of the plate is an important factor. The same torque can be created with two plates of different resistivity, but a given torque is obtained at higher speeds with a plate of higher resistivity.

5) The thickness of the plate is important. The thinner the plate, the higher the maximum torque. The maximum torque will also be at higher speeds.

6) The distance between the plate and the rotor magnet is critical.

The results obtained are equivalent to slip curves of asynchronous motors. The difference between the measures and the FEM model (Fig. 9) can be explained by the simplifying assumptions, by an uncertainty on the magnetic flux density amplitude measurement, and by a mechanical coupling through the air between the brake and the plate.

To make a motor torque measurement with this method, one needs to vary the distance between the magnet and the plate to vary the measured braking torque.

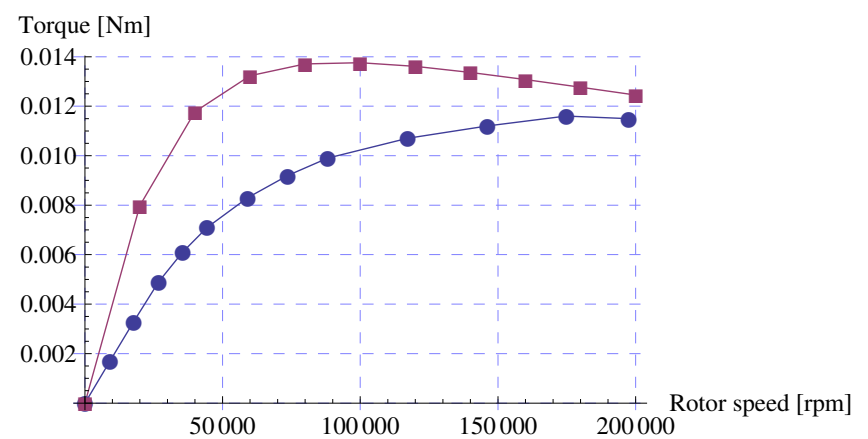

Fig. 9. Comparison between the torque measured with the eddy current brake (dots) and the simulation using the finite element software (squares). The distance between the plate and the brake is $0.25 \mathrm{~mm}$.

\section{MOTOR TORQUE MEASUREMENT: METHOD COMPARISON}

The inertial method (indirect) presented in the section III is validated (Fig. 10) through the eddy current brake method (direct). Since the maximum braking torque of the eddy current braking device is $11.6 \mathrm{mNm}$, the validation measurements were done only at low torque. 


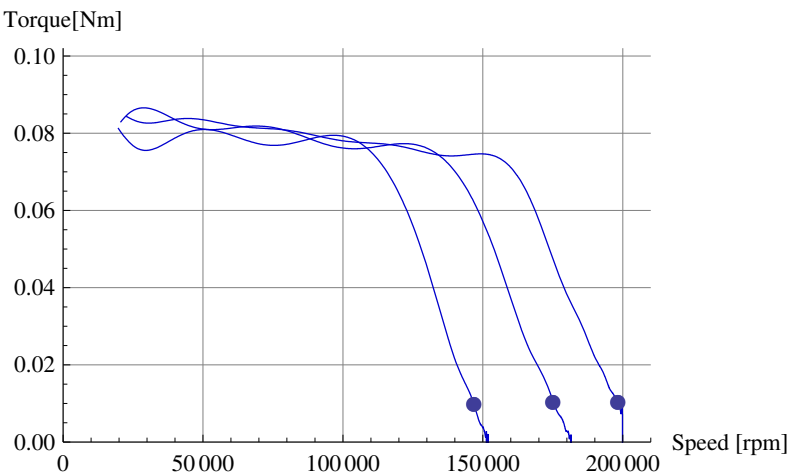

Fig. 10. Validation of the inertial method using the eddy current brake method. The applied voltage is $30 \mathrm{~V}, 60 \mathrm{~V}, 68 \mathrm{~V}$. A pulse width modulation limits the current and hence the torque in the first part of the 3 curves. The 3 points represents 3 torque measurements using the eddy current brake method.

\section{BALL BEARINGS TORQUE MEASUREMENT: DIRECT METHOD}

In a ball bearing, there are many parameters which influence the friction torque: the dimensions, the rolling paths materials, the balls materials, the contact angles, the construction precision, the speed, the preload and the lubrification.

Theoretical models are available in the literature [5], [6] to estimate this torque. However, due to the very high speeds, the uncertainties of many model parameter values, the accuracy of such models may be poor [7].

Among articles about the use of ceramic ball bearings for high speed applications [8], there are not many ones about friction torque: we can cite [9], which gives an empirical model for a given design and speed range.

Therefore, a setup was done to do an experimental model for the ball bearings considered for our prototype.

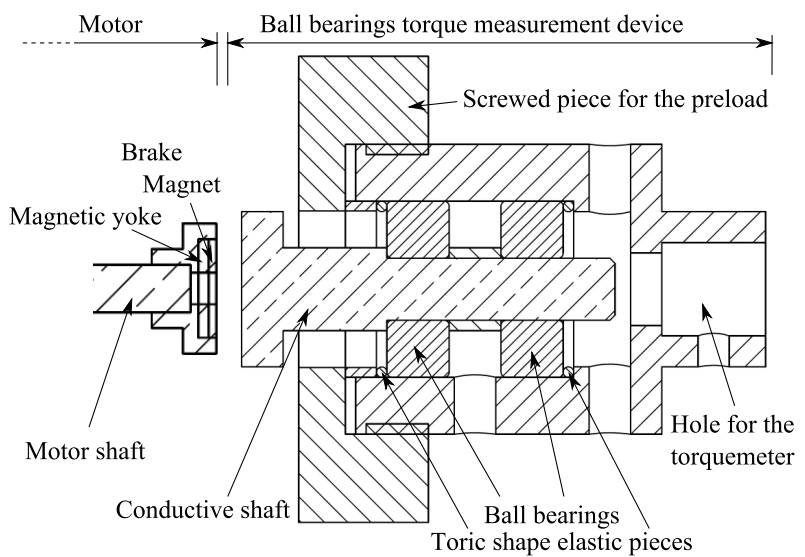

Fig. 11. Bearings friction torque measurement setup: the conductive shaft driven from the left, the two ball bearings, a hole on the right is for the torquemeter.

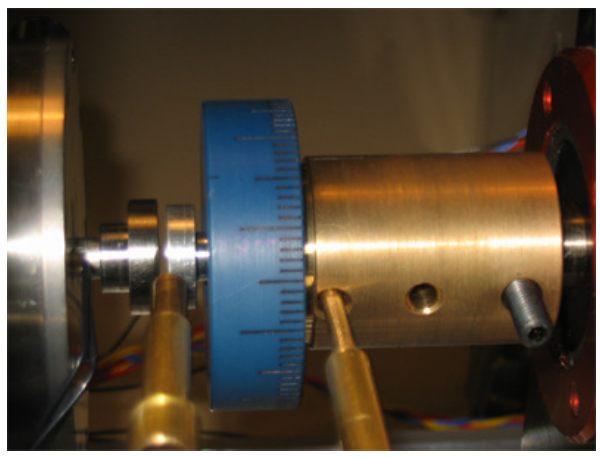

Fig. 12. Picture of the bearing friction torque measurement setup.

TABLE II

DIMENSIONS AND PROPERTIES OF THE MEASURED BALL BEARINGS.

$\begin{array}{ll}\text { Inner diameter } & 6 \mathrm{~mm} \\ \text { Outer diameter } & 17 \mathrm{~mm} \\ \text { Axial length } & 6 \mathrm{~mm} \\ \text { Contact angle } & 15^{\circ} \\ \text { Ball type } & \text { Ceramic }\end{array}$

\section{A. The setup}

As shown in Fig. 11, two ball bearings are mounted on a conductive shaft, which is in our case made of aluminium. As in the case of the eddy current brake, a multipolar axially magnetized permanent magnet is mounted at the end of the shaft of the motor and drives the conductive shaft. Eddy currents are created in the conductive shaft, so the coupling is contactless. The reaction torque $T_{2}$ is measured on the fixed part which surrounds the bearings.

Two toric shape elastic pieces stand at the two sides of the bearings. The preload is adjusted on the bearings through a screwed piece (on the left, in Figs 11 and 12).

The data of the tested bearings are shown in Tab. II.

\section{B. Measurement procedure}

As the coupling between the motor shaft and the conductive shaft is done by the mean of eddy currents, there is a speed difference between the two shafts. Let $f$ be the conductive shaft rotation frequency, $f_{m}$ the motor rotor rotation frequency and $\Delta f$ the frequency difference between them:

$$
\Delta f=f_{m}-f
$$

First we need to relate $\Delta f$ to the torque applied on the conductive shaft. We fix the conductive shaft $(f=0)$ and run the motor. We measure the torque $T_{1}$ as a function of $\Delta f=f_{m}$, which gives us the slip curve:

$$
T_{1}=g_{1}(\Delta f)
$$

Then we let the conductive shaft rotate freely. We drive the motor at different speeds. The reaction torque $T_{2}$ is measured as a function of $f_{m}$ :

$$
T_{2}=g_{2}\left(f_{m}\right)
$$


TABLE III

MEASURED PARAMETERS OF THE BALL BEARINGS TORQUE MODEL.

\begin{tabular}{l|l|l} 
Preload & $17 \mathrm{mNm}$ & $35 \mathrm{mNm}$ \\
\hline$c_{1}$ & $5.23 \times 10^{-9} \mathrm{mNm}$ & $1.16 \times 10^{-8} \mathrm{mNm}$ \\
$c_{2}$ & 1.59 & 1.51 \\
$c_{3}$ & $2.28 \times 10^{-4} \mathrm{mNm}$ & $4.28 \times 10^{-4} \mathrm{mNm}$
\end{tabular}

As there is no speed sensor on the conductive shaft, its rotation frequency is deduced using the slip curve:

$$
f=f_{m}-g_{1}^{-1}\left(T_{2}\right)
$$

\section{The results}

The results are shown in Fig. 13. The friction torque of the ball bearings is dependent on the speed and on the preload. The measurements include the mechanical coupling through the air. Since the torque is quite small, the measurements were difficult to realize.

The results are fitted using the following model:

$$
T_{2}=c_{1}\left(\frac{f}{[\mathrm{hz}]}\right)^{c_{2}}+c_{3}
$$

The results are shown in Tab. III.

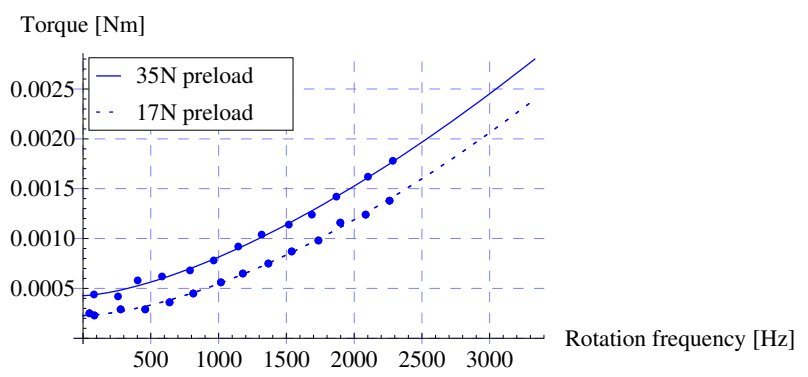

Fig. 13. Brake torque as a function of speed of a pair of ball bearings, for different preloads.

\section{CONCLUSION}

\section{A. Motor torque measurement: Eddy current brake}

The FEM model gave us an understanding of the brake. The eddy current brake torque measurement method is good for continuous torque measurements. For mechanical stress reasons, the high speeds limit the outer diameter of the brake, which limits the maximum braking torque. It was possible to test the motor up to $238 \mathrm{~W}$ and not the needed $2 \mathrm{~kW}$. The measurements are time consuming. The problem is also the dissipation of the heat.

\section{B. Motor torque measurement: Inertial method}

The inertial method allows making measurements that keeps the temperature of the motor homogeneous; it allows to make very high torque measurement; the measurement is very fast $(0.380 \mathrm{~s}$ to do the measurement for a range from 0 to $200 \mathrm{krpm}$ ); it is not possible to make continuous torque measurement using it.

\section{Ball bearings torque measurement: Direct method}

The model which is derived from these measurements is very useful for the global modeling of the motor [3].

\section{ACKNOWLEDGMENT}

The authors want to thank Bernard Reudet, Moving Magnet Technologies $S A$ and Sonceboz $S A$ for their support.

\section{REFERENCES}

[1] A. Chiba and T. Fukao, "Super high speed electrical machines," 2004. IEEE Power Engineering Society General Meeting, pp. 1272-1275, 2004.

[2] L. Zhao, C. Ham, L. Zheng, T. Wu, K. Sundaram, J. Kapat, and L. Chow, "A highly efficient 200000 RPM permanent magnet motor system," in Magnetics, IEEE Transactions on, vol. 43, no. 6, Washington, DC, USA, June 2007, pp. 2528-2530.

[3] P.-D. Pfister and Y. Perriard, "Design procedure for a very high speed slotless permanent magnet motor," in ELECTRIMACS 2008, 9th International Conference on Modeling and Simulation of Electric Machines, Converters and Systems, 2008.

[4] T. W. Nehl, B. Lequesne, V. Gangla, S. A. Gutkowski, M. J. Robinson, and T. Sebastian, "Nonlinear two-dimensional finite element modeling of permanentmagnet eddy current couplings and brakes," in Magnetics, IEEE Transactions on, vol. 30, Miami, FL, USA, Sept. 1994, pp. 30003003.

[5] T. A. Harris and M. N. Kotzalas, Rolling bearing analysis. Volume I. Boca Raton : CRC Press c/o Taylor \& Francis, 2007.

[6] — Rolling bearing analysis. Volume II. Boca Raton : CRC Press c/o Taylor \& Francis, 2007.

[7] B. Bossmanns and J. F. Tu, "A power flow model for high speed motorized spindles-heat generation characterization," Journal of Manufacturing Science and Engineering, vol. 123, no. 3, pp. 494-505, 2001.

[8] F. Schweizer and K. Adleff, "Rolling bearings in turbocharger application," MTZ, vol. 67, pp. 16-19, 92006.

[9] K. Tanimoto, K. Kajihara, and K. Yanai, "Hybrid ceramic ball bearings for turbochargers." SAE Transactions: Journal of Materials \& Manufacturing, vol. 109, pp. 763-775, 2000. 